\title{
Editorial: Innovation for Local and Global Impact
}

\author{
Stoyan Tanev, Editor-in-Chief \\ Gregory Sandstrom, Managing Editor
}

Welcome to the August 2019 issue of the Technology Innovation Management Review. This issue has a special significance since it signals the formation of a new Managing Editorial Board, including Dr. Stoyan Tanev as Editor-in-Chief and Dr. Gregory Sandstrom as Managing Editor. The TIM Review journal also has anew Board of Associate Editors and International Advisory Board. It is our pleasure to take over the editorship from Chris McPhee who, after 9 years of successfully driving the journal to where it is now, has taken on an innovation management role with Agriculture and Agri-Food Canada's Living Laboratories Initiative.

The August issue includes papers presented at ISPIM Connects Ottawa, a three-day event held in Ottawa, Canada, from April 7-10, 2019. ISPIM Connects Ottawa brought together world-renowned innovation managers, researchers, and business and thought leaders to share insights on specific local and global innovation challenges as well as general innovation management topics. The TIM Review and its associated academic program at Carleton University, the TIM Program (timprogram.ca), were proud to be the local hosts of the event in collaboration with the International Society for Professional Innovation Management (ISPIM; ispiminnovation.com) and local partners.

The topic of the ISPIM Connects Ottawa Conference was Innovation for Local and Global Impact with a focus on three challenges: scaling start-ups, adopting AI and analytics, and innovating with Government. The articles included in this issue focus on various topics related to entrepreneurship and innovation. For example, the paper by Vyas and Vyas, "Human capital, its constituents, and entrepreneurial innovation," summarizes the results of an empirical study based on data about over 200,000 businesses provided in the Global Entrepreneurship Monitor's (GEM) Adult Population Surveys (APS) from 2005 to 2011 in 96 countries. The paper explains the failure of previous research to extend human capital theory to innovation. The reason for the failure is found due to overlooking the conflicting influences and interplay of education and experience. The authors present a conceptual and empirical case against the use of work experience as a constituent of human capital. Their hierarchical exploration of innovation antecedents shows that, at the individual level, being young and recently educated are significant predictors of innovation. At the societal level however, national wealth dampens the negative effect of age on innovation and accentuates the positive effect of education.

The paper by Muegge and Reid "Elon Musk and SpaceX: A case study of entrepreneuring as emancipation" employs a theoretical lens to explain and interpret the entrepreneuring activities of Elon Musk that led to the launch and growth of SpaceX. The authors apply an event study approach that combines case methods and process theory methods using publicly-available sources to develop six examples of seeking autonomy, seven examples of authoring, and four examples of making declarations- the three core elements of the emancipation perspective on entrepreneuring. The paper contributes to entrepreneurship theory and practice by adding to the corpus of descriptive case studies that examine entrepreneuring as an emancipatory process. The key contribution of the paper is to demonstrate the emancipation perspective's value as an organizing framework that accommodates wealthcreation, hubris, bricolage, effectuation, and other perspectives on entrepreneurship and innovation, as partial and complementary explanations of the motivations and processes behind entrepreneuring activities.

Gordon, Rohrbeck and Schwarz's paper, "Escaping the 'faster horses' trap: Bridging strategic foresight and design-based innovation", explores how methods from the strategic foresight field may advance design thinking. The study offers a comparison of representative models from each field and shows how they may be assembled together to shape a foresight-informed design-based innovation approach. The suggested framework incorporates academically and practically validated strategic foresight processes into design thinking, while also respecting the integrity of the design thinking model as is, thus adding to it rather than seeking to revise it. The authors discuss the benefits of strategic foresight, arguing that it takes design thinking beyond reliance on user observation, and therein helps to mitigate its vulnerability to significant or unforeseen contextual changes.

The paper by Omar Valdez-De-Leon "How to develop a digital ecosystem - a practical framework" provides a 


\section{Editorial: Innovation for Local and Global Impact}

\section{Stoyan Tanev \& Gregory Sandstrom}

literature review and an analysis of empirical observations from expert surveys and interviews. He suggests a practical framework for both established organizations and entrepreneurs who are interested to better understand, plan, and navigate the new paradigm of digital ecosystems. The framework has three main elements - platform, market expectation and network effects, and six enablers - application programming interfaces (APIs), communities, spearhead products and services, support functions, revenue model and governance. The implementation of the six enablers allows for flexibility depending on the context, the maturity of the ecosystem, and the strategy being pursued. The framework will be valuable to practitioners who can apply it as a guiding tool when developing their digital ecosystem strategies, be it as an ecosystem leader, or as a participant in an existing ecosystem.

Weiss and Muegge's paper "Conceptualizing a new domain using topic modeling and concept mapping: A case study of managed security services for small businesses" shows how topic modeling and concept mapping can be used to conduct a literature review in a new domain. The paper makes two contributions. First, it uses topic modeling to map out the literature in the new domain. Topic modeling provides an alternative to manual clustering of articles and enables the identification of non-obvious connections between ideas expressed in a collection of articles. Second, it identifies the underlying concepts in the new domain, as well as their relationships by creating a concept map from the extracted topics. As a case study, the paper reviews the recent literature at the intersection of managed security services and small businesses, and explores how elements of the managed security services concept apply to small businesses. More specifically, the paper highlights a crucial shift from operations to risk considerations when small businesses outsource their security. The key contribution is to suggest complementarity between concept mapping and topic modelling analysis.

For other future issues, we are accepting general submissions of articles on technology entrepreneurship, innovation management, and other topics relevant to launching and growing technology companies and solving practical problems in emerging domains. Please contact us (timreview.ca/contact) with potential article topics and submissions, and proposals for future special issues.

Stoyan Tanev, Editor-in-Chief

Gregory Sandstrom, Managing Editor

\section{About the Editors}

Stoyan Tanev, PhD, MSc, MEng, MA, is Associate Professor of Technology Entrepreneurship and Innovation Management associated with the Technology Innovation Management (TIM) Program, Sprott School of Business, Carleton University, Ottawa, ON, Canada. Before re-joining Carleton University, Dr. Tanev was part of the Innovation and Design Engineering Section, Faculty of Engineering, University of Southern Denmark (SDU), Odense, Denmark.

Dr. Tanev has a multidisciplinary background including MSc in Physics (Sofia University, Bulgaria), PhD in Physics (1995, University Pierre and Marie Curie, Paris, France, co-awarded by Sofia University, Bulgaria), MEng in Technology Management (2005, Carleton University, Ottawa, Canada), MA in Orthodox Theology (2009, University of Sherbrooke, Montreal Campus, QC, Canada) and $\mathrm{PhD}$ in Theology (2012, Sofia University, Bulgaria).

Dr. Stoyan Tanev has published multiple articles in several research domains. His current research interests are in the fields of technology entrepreneurship and innovation management, design principles and growth modes of global technology start-ups, business analytics, topic modeling and text mining. He has also an interest in interdisciplinary issues on the interface of the natural and social sciences.

Gregory Sandstrom is Managing Editor of the TIM Review. Former associate professor of mass media and communications at the European Humanities University and affiliated associated professor at the Social Innovations Laboratory, Mykolas Romeris University in Vilnius, Lithuania. PhD from St. Petersburg State University and the Sociological Institute of the Russian Academy of Sciences, sector on sociology of science, postdoctoral research fellow at the Lithuanian Science Council and Autonomous National University of Mexico's Institute for Applied Mathematics and Systems. Promoter and builder of blockchain distributed ledger technology systems and digital extension services.

Citation: Tanev, S. \& G. Sandstrom 2019. Editorial:

Innovation for Local and Global Impact. Technology

Innovation Management Review, 9(8): 3-4.

http://doi.org/10.22215/timreview/1256

Keywords: ISPIM, human capital, business models, emancipation, entrepreneurship, design thinking, strategic

foresight, digital ecosystems, topic modeling 